Annales Geophysicae (2002) 20:717-727 (C) European Geophysical Society 2002

\title{
Transport of potential vorticity and Eliassen-Palm fluxes for two contrasting years: 1995-1996 (La Niña) and 1997-1998 (El Niño)
}

\author{
S. H. Franchito, V. Brahmananda Rao, J. P. R. Fernandez, and S. R. Chapa \\ Centro de Previsão de Tempo e Estudos Climáticos, CPTEC Instituto Nacional de Pesquisas Espaciais, INPE CP 515, \\ 12201-970, São José dos Campos, SP, Brazil
}

Received: 16 August 2000 - Revised: 5 December 2001 - Accepted: 18 December 2001

\begin{abstract}
Potential vorticity transport (PV)-Eliassen and Palm (EP) cross sections are studied for two contrasting years: 1995-1996 (La Niña) and 1997-1998 (El Niño). The results show that the largest differences in PV transport-EP fluxes between El Niño and La Niña events occur in winter in both hemispheres, but the changes are higher in the Northern Hemisphere. PV transport-EP fluxes are stronger in both July 1997 and January 1998 than in July 1995 and January 1996, respectively, indicating stronger baroclinic activity in the El Niño year compared to the La Niña year. The changes in PV transport seem to be due mainly to the changes in eddy heat fluxes. Due to the increase in the wind shear the Eady growth rate is stronger in the 1997-1998 El Niño compared to 19951996 La Niña. Consequently, the zonal winds are stronger in the El Niño event, although the location of the jet streams is almost the same in both the contrasting years. However, in the Southern Hemisphere, there are two regions of maxima Eady growth rate in July 1997 and a double jet is observed while a single jet is seen in July 1995 associated with only one maximum of Eady growth rate. In the case of summer, there is little difference in PV transport-EP fluxes between the two contrasting years in the hemispheres, although they are slightly higher in the El Niño event than in the La Niña event.
\end{abstract}

Key words. Meteorology and atmospheric dynamics (climatology; general circulation)

\section{Introduction}

Due to their influence on global climate, El Niño-La Niña events have received much attention during the last decades. Several studies have been made in order to investigate the development and the associated climatic anomalies of these events and their consequences of global climate change (Chen, 1983; Kousky et al., 1984; Kayano et al., 1989; Ki-

Correspondence to: S. H. Franchito (fran@cptec.inpe.br) ladis and Diaz, 1989; Ropelewski and Halpert, 1996; Grimm et al., 1998; Trenberth et al., 1998; Hansen et al., 1999; and many others). Pacific cold episode (La Niña) conditions prevailed during 1995-1996, while one of the strongest Pacific warm episodes (El Niño) in the historical record occurred from the boreal spring of 1997 through autumn of 1998 (Coughlan, 1999; Barnston et al., 1999; Changnon, 1999). The development of this episode relative to the previous events was discussed by Wang and Weisberg (2000). The indices of Niño 3 region $\left(5^{\circ} \mathrm{S}-5^{\circ} \mathrm{N}, 150^{\circ}-90^{\circ} \mathrm{W}\right)$ sea surface temperature (SST) and Niño 4 region $\left(5^{\circ} \mathrm{S}-5^{\circ} \mathrm{N}\right.$, $\left.160^{\circ} \mathrm{E}-150^{\circ} \mathrm{W}\right)$ zonal wind anomalies show that the $1997-$ 1998 El Niño event is the strongest on record (see Fig. 1 of Neelin et al., 2000). El Niño-La Niña events seem to have strong influence on the activity of baroclinic waves. The occurence of cyclogenesis over South America is more during the years of negative Southern Oscillation index (El Niño years) and less during the years of positive Southern Oscillation index (La Niña) (Gan and Rao, 1991).

In the present paper, we study the meridional transport of quasi-geostrophic potential vorticity (PV) and EliassenPalm (EP) fluxes for two above mentioned contrasting years: 1995-1996 and 1997-1998. We attempt to investigate the seasonal variations of eddy fluxes of heat, momentum and $\mathrm{PV}$ in these contrasting years. Analysis on PV transport-EP divergence gives a comprehensive illustration of the activity of baroclinic waves. PV transport corresponds to divergence of EP flux (Edmon et al., 1980; Hoskins, 1983). EP vectors provide information on the relative roles wave heat and momentum forcing, and Rossby wave energy propagation, and the contours of EP divergence indicate the net effect of waves on PV transport and mean flow.

\section{Data and methodology}

The meridional transport of quasi-geostrophic $\mathrm{PV}\left(\mathrm{v}^{\text {‘ }} \mathrm{Q} \text { ' }\right)_{o}$ is evaluated using the formula (Wiin-Nielsen and Sela, 1971; 
a)

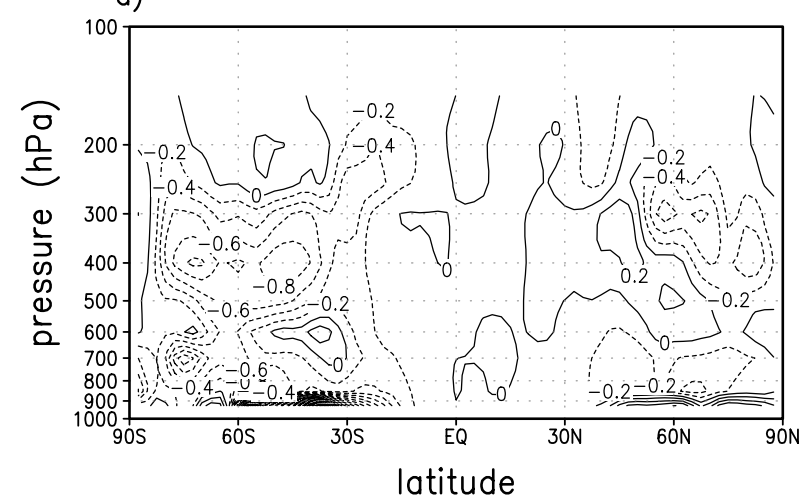

c)

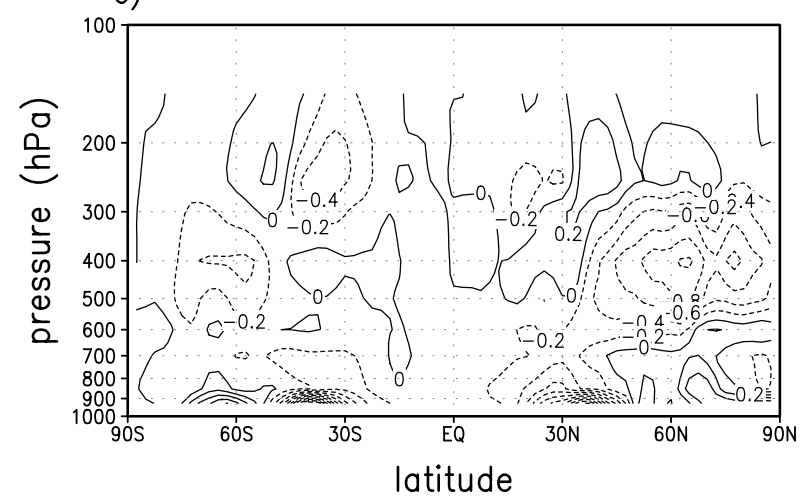

b)

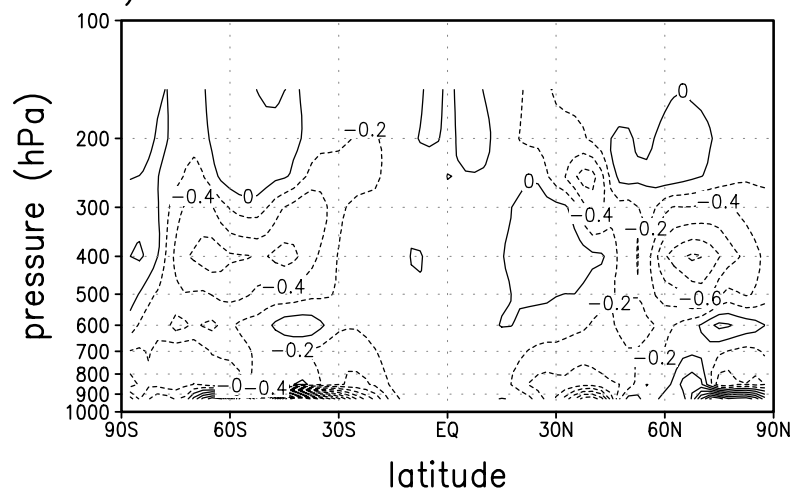

d)

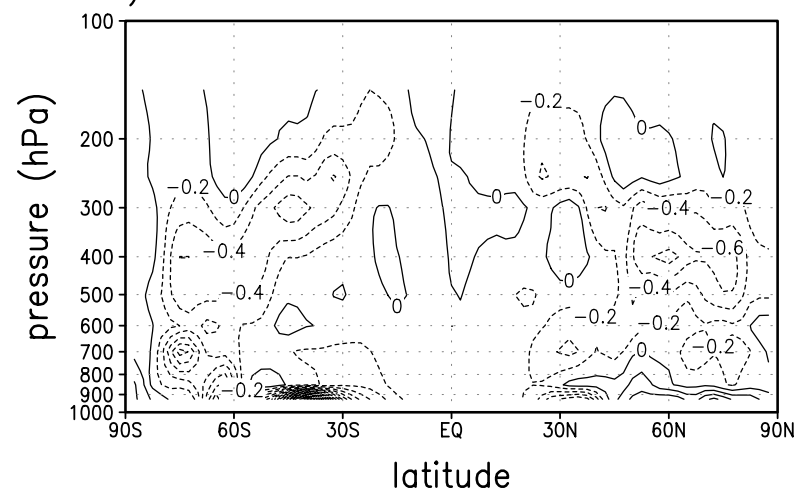

Fig. 1. Zonally-averaged PV transport for: (a) July 1997, (b) October 1997, (c) January 1998 and (d) April 1998. Units, $10^{-4} \mathrm{~m} \mathrm{~s}^{-2}$.

a)

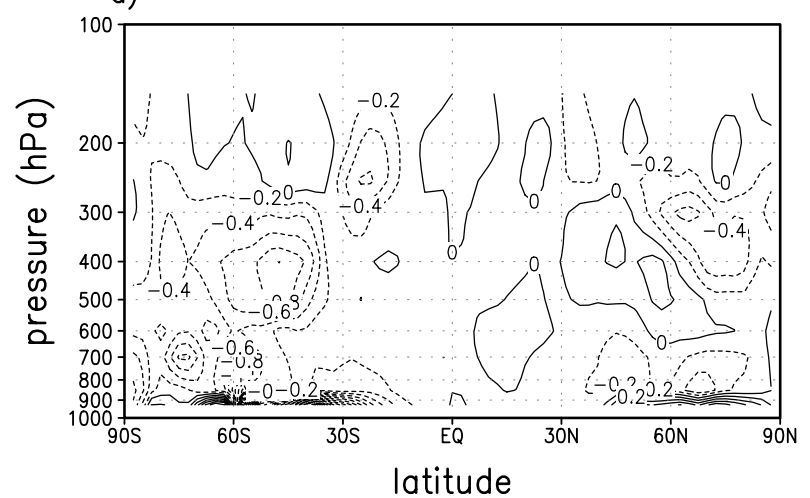

c)

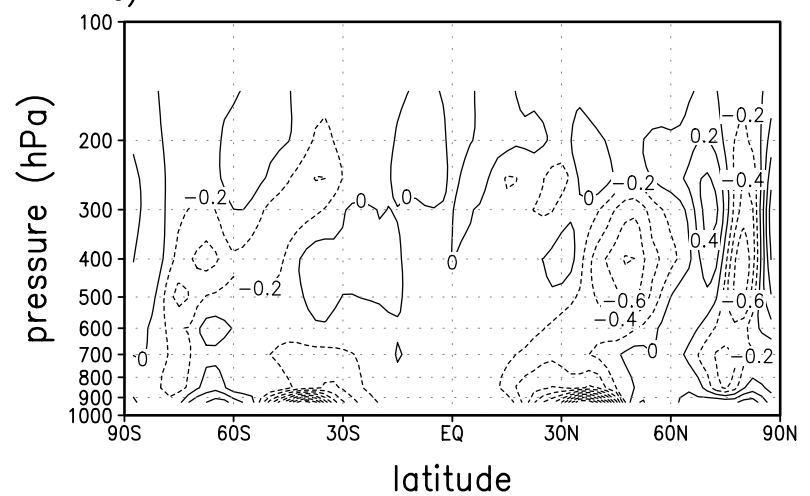

b)

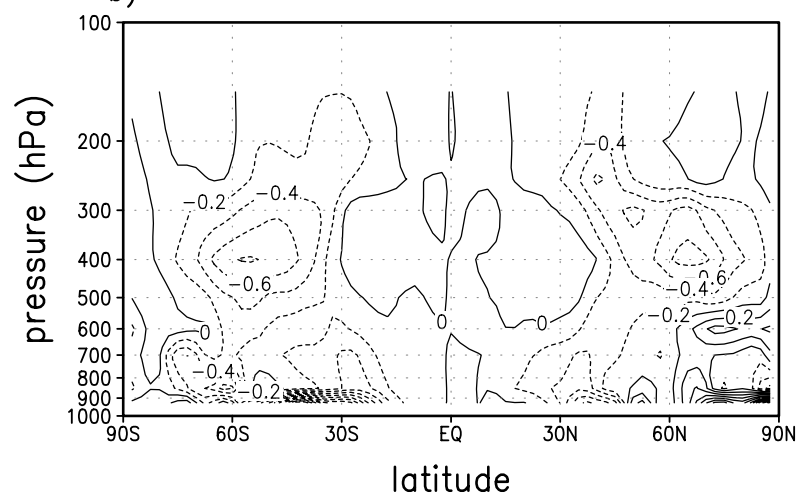

d)

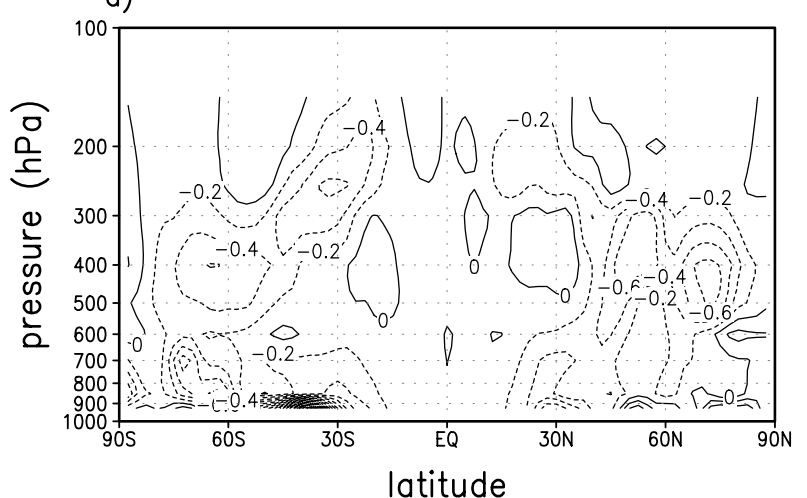

Fig. 2. Same as in Fig. 1 but for: (a) July 1995, (b) October 1995, (c) January 1996 and (d) April 1996. 
Franchito and Rao, 1991):

$$
\begin{gathered}
\left(v^{\prime} Q^{\prime}\right)_{o}=1 / a \cos ^{2} \varphi \partial\left[\left(u^{\prime} v^{\prime}\right)_{o} \cos ^{2} \varphi\right] / \partial \varphi- \\
\partial\left[f_{o} R\left(v^{\prime} T^{\prime}\right)_{o} / \sigma p\right] / \partial p,
\end{gathered}
$$

where $\left(\mathrm{u}^{\prime} \mathrm{v} \text { ' }\right)_{o}$ and $\left(\mathrm{v}^{\prime} \mathrm{T} \text { ' }\right)_{o}$ are the meridional transport of momentum and heat, respectively; a, the Earth's radius; $\mathrm{f}_{o}$, the Coriolis parameter at $45^{\circ} \mathrm{N}(\mathrm{S})$; R, the gas constant; $\varphi$, the latitude; and $\mathrm{p}$ is the pressure level. The subscript "o" corresponds to the zonally-averaged values.

The theory and use of EP cross sections as a diagnostic for disturbances on zonal mean wind are given in detail by Edmon et al. (1980) and Hoskins (1983). The quasi-geostrophic EP flux vector $(\boldsymbol{F})$ is given by:

$$
\begin{aligned}
\boldsymbol{F}= & \left(F_{\varphi}, F_{z}\right)=p_{s} a \cos \varphi \\
& {\left[-\left(u^{\prime} v^{\prime}\right)_{o}, R f / H N^{2}\left(v^{\prime} T^{\prime}\right)_{o}\right], }
\end{aligned}
$$

where the symbols have the usual meaning.

If $\boldsymbol{F}$ is represented in a latitude-height grid, $\boldsymbol{F}$ will appear erroneously divergent even when $\boldsymbol{\nabla} \cdot \boldsymbol{F}=0$. Edmon et al. (1980) overcame this problem by introducing a factor $2 \pi$ a $\cos \varphi$ in expression (2). In this case, the pattern of arrows of the vector $\mathcal{F}=2 \pi$ a $\cos \varphi \boldsymbol{F}$, whose horizontal and vertical components are proportional to $\mathcal{F}_{\varphi}$ and $\mathcal{F}_{z}$ will look non-divergent if and only if $\boldsymbol{\nabla} \cdot \boldsymbol{F}=0$. Thus, the arrows in the EP cross sections have the components:

$$
\begin{aligned}
\mathcal{F}= & \left(\mathcal{F}_{\varphi}, \mathcal{F}_{z}\right)=p_{s} 2 \pi a^{2} \\
& {\left[-\cos \varphi^{2}\left(u^{\prime} v^{\prime}\right)_{o}, R f / H N^{2} \cos \varphi^{2}\left(v^{\prime} T^{\prime}\right)_{o}\right] . }
\end{aligned}
$$

More details about the methodology for the evaluation of the PV transport and EP cross sections are given by WiinNielsen and Sela (1971) and Edmon et al. (1980), respectively.

In the present study, the PV transport and EP cross sections are determined using the reanalysis data from the National Centers for Environmental Prediction (NCEP)/National Center for Atmospheric Research (NCAR) for 1995-1996 and 1997-1998. In order to study the seasonal variation, monthly means for these years are used. On the other hand, for studying the transient baroclinic waves, data of the zonallyaveraged momentum and heat fluxes by transient eddies are used. The NCEP/NCAR reanalysis data are devoid of errors due to changes in models physics and resolution. A detailed description of the assimilation system and output is given by Kalnay et al. (1996).

\section{Results}

Since the El Niño 1997-1998 event began approximately in the boreal spring of 1997, and diminished in May 1998, we analyse the period from July 1998 (1995) through April 1998 (1996), when the El Niño (La Niña) event was stronger.

Figures 1a-d show, respectively, the meridional transport of PV for July 1997 (austral winter), October 1997 (austral spring), January 1998 (boreal winter) and April 1998 (boreal spring). Figures 2a-d show the same for July 1995, October 1995, January 1996 and April 1996. In general, the spatial pattern of PV transport in all figures agrees with those obtained in previous studies (Wiin-Nielsen and Sela, 1971; Franchito and Rao, 1991). PV transport is negative over almost the entire troposphere, with the exception of a thin layer near the surface and some regions in the middle and upper troposphere. This spatial pattern is observed at midlatitudes and high-latitudes in all months, except in summer. In July (HN) and January (HS), a large region of positive PV transport is observed in the middle troposphere at midlatitudes. Since the PV gradient is positive over most of the atmosphere the negative PV transport implies predominantly, down-gradient fluxes (Figs. 3a-d and Figs. 4a-d). The positive PV fluxes are not up-gradient because they occur in regions where PV gradient is small or negative. The configuration of PV transport shown in Figs. 1 and 2, has important implications for the generation of baroclinic waves because the changes in the direction of PV fluxes satisfies the requirements for the occurrence of baroclinic instability in the troposphere (Charney and Stern, 1962). From Figs. 1a-d and Figs. 2a-d it can be seen that PV transport is stronger in winter in both El Niño and La Niña events.

Figures 5a-d show the differences (El Niño minus La Niña) in the PV transport given in Figs. 1 and 2. It can be noted in this figure that in general, PV is higher in the El Niño 1997-1998 event compared to the La Niña 1995-1996 event. The highest differences occurred in boreal winter (January) and austral winter (July). So, we will concentrate our analysis on the January and July conditions. As noted in Figs. 5a and c, the increase in PV transport is higher in high-latitudes in the middle and upper troposphere. The highest changes in $\mathrm{PV}$ transport occur at $60^{\circ} \mathrm{N}-70^{\circ} \mathrm{N}$ in the $\mathrm{NH}$ and $60^{\circ} \mathrm{S}-$ $75^{\circ} \mathrm{S}$ in the $\mathrm{SH}$, around $400 \mathrm{hPa}$. These changes in PV transport are related to the changes in meridional transport of sensible heat and momentum. As can be seen in Figs. 6a-b, in the $\mathrm{NH}$ winter (January), eddy heat flux shows two maxima at low levels in the two contrasting years: around $40^{\circ} \mathrm{N}-$ $50^{\circ} \mathrm{N}$ and $80^{\circ} \mathrm{N}$, respectively. It can be noted from Fig. $6 \mathrm{c}$ that the highest differences in eddy heat flux between January 1998 and January 1996 occur in high-latitudes $\left(60^{\circ} \mathrm{N}-\right.$ $70^{\circ} \mathrm{N}$ ) in the middle and upper troposphere, as in the case of PV transport (Fig. 5c). Figure 6c also shows that there is a region in the mid-latitudes in the upper troposphere, where eddy heat fluxes in January 1998 are weaker than in January 1996. This is associated with the region where PV transport in January 1998 is weaker than in January 1996, as shown in Fig. 5c. From Figs. 7a and b, it can be noted that the maximum eddy momentum, flux which occurs in the upper troposphere around $30^{\circ} \mathrm{N}$, is slightly weaker in January 1998 than in January 1996. Also, an up-gradient flux at the highlatitudes of the NH is found in January 1996 while in January 1998 the up-gradient flux is stronger and displaced towards the mid-latitudes. Thus, it can be inferred from Figs. 5c, 6c and $7 \mathrm{c}$ that in the upper troposphere, between $30^{\circ} \mathrm{N}-60^{\circ} \mathrm{N}$, both the decrease in eddy fluxes of heat and momentum con- 
a)

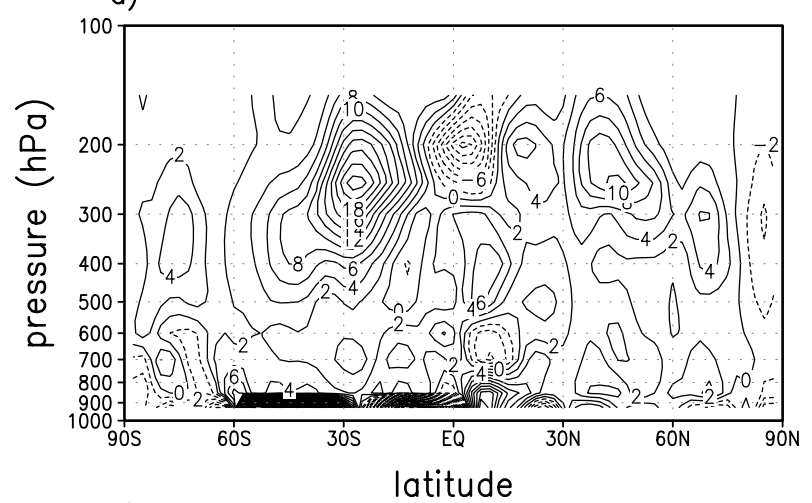

c)

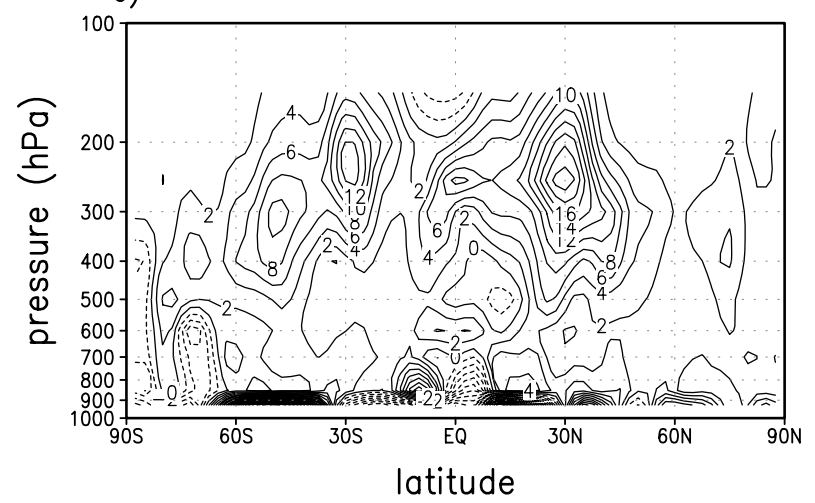

b)

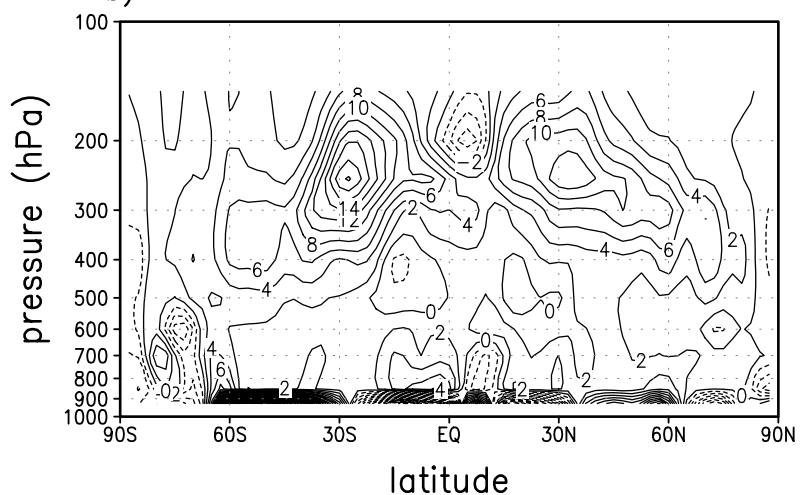

d)

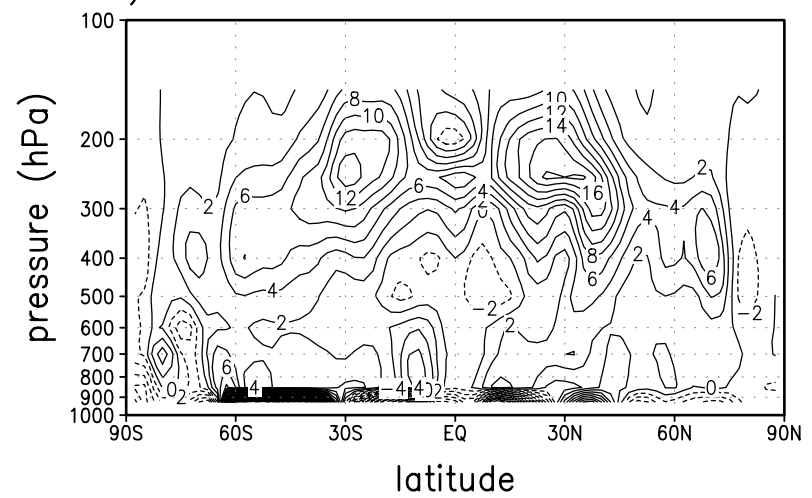

Fig. 3. Zonally-averaged PV gradient for: (a) July 1995, (b) October 1995, (c) January 1996 and (d) April 1996. Units, $10^{-11} \mathrm{~m}^{-1} \mathrm{~s}^{-1}$.

a)

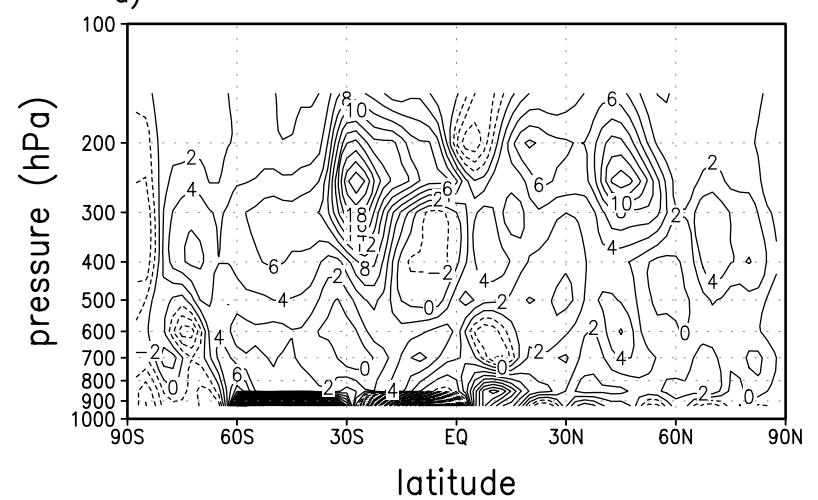

c)

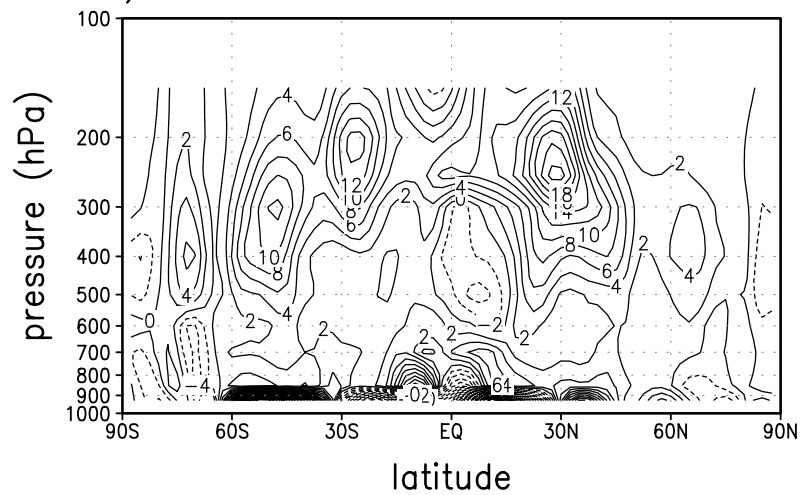

b)

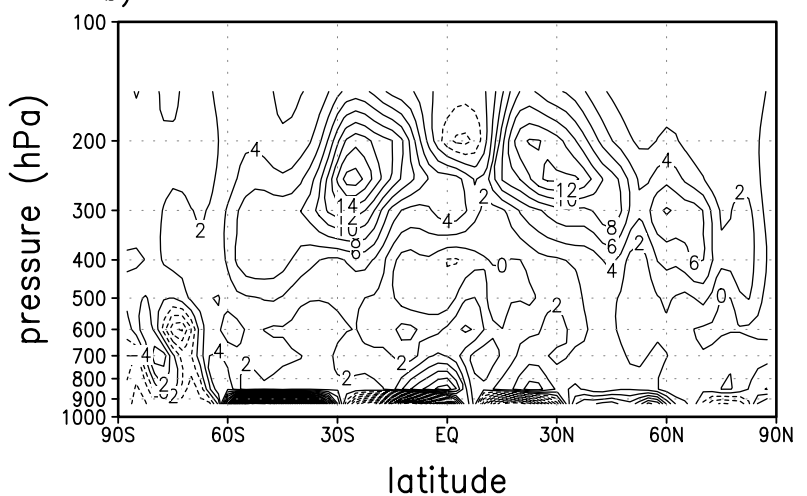

d)

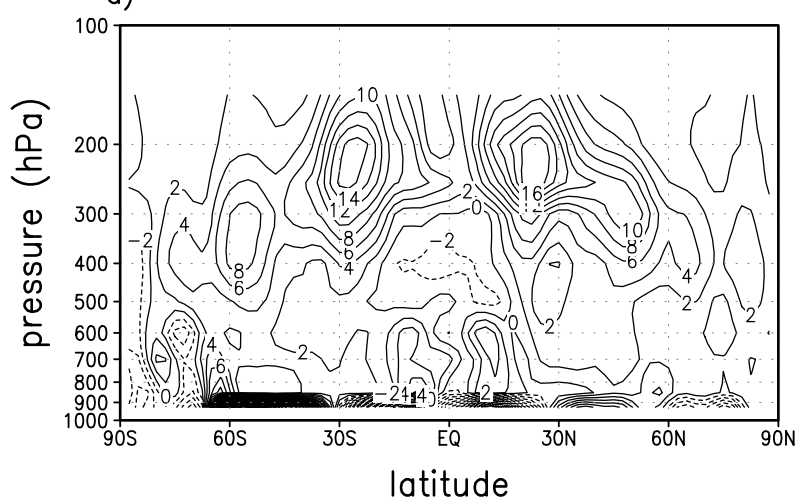

Fig. 4. Same as Fig. 3 but for (a) July 1997, (b) October 1997, (c) January 1998 and (d) April 1998. 
a)

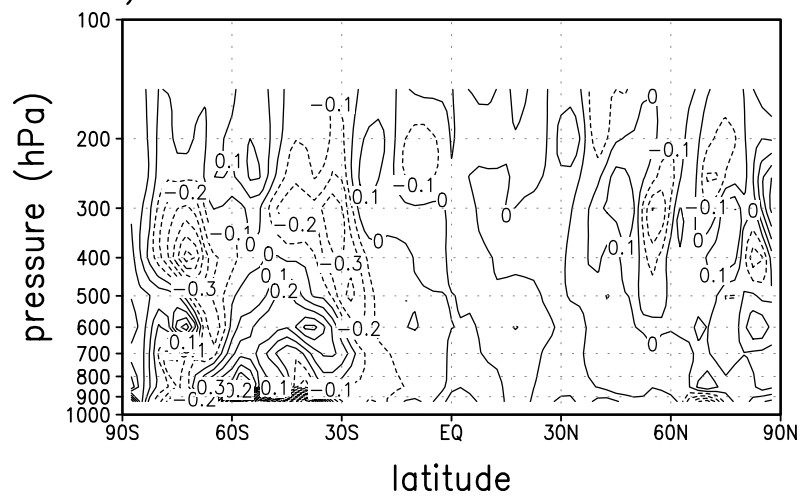

c)

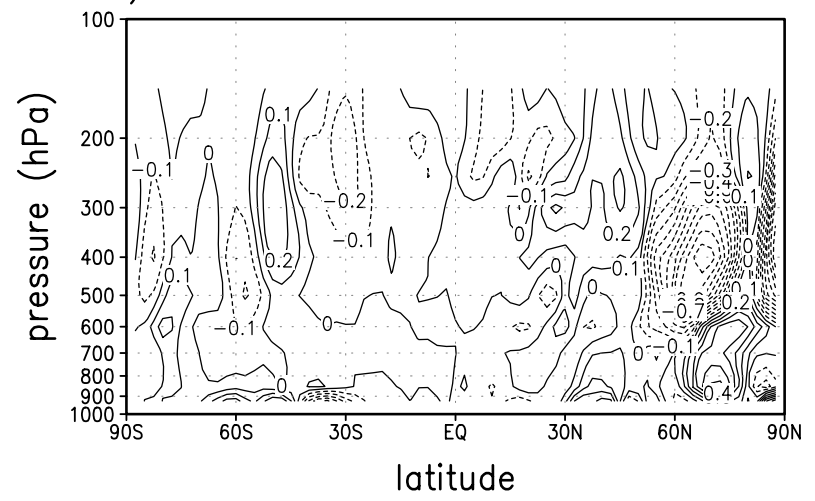

b)

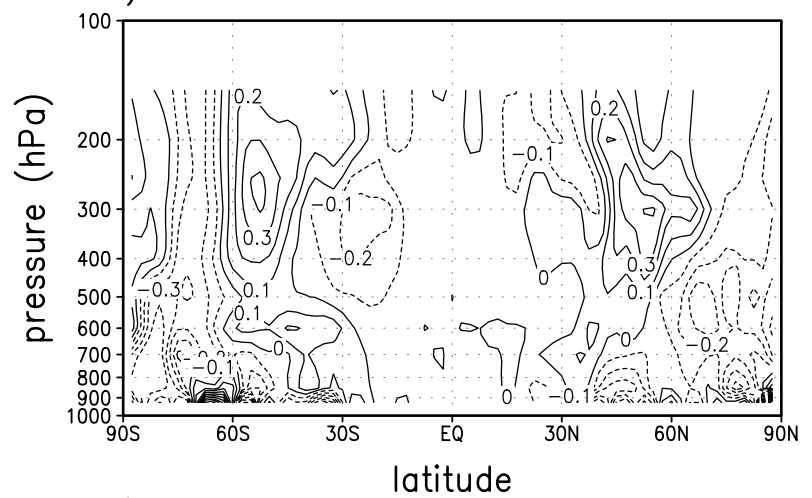

d)

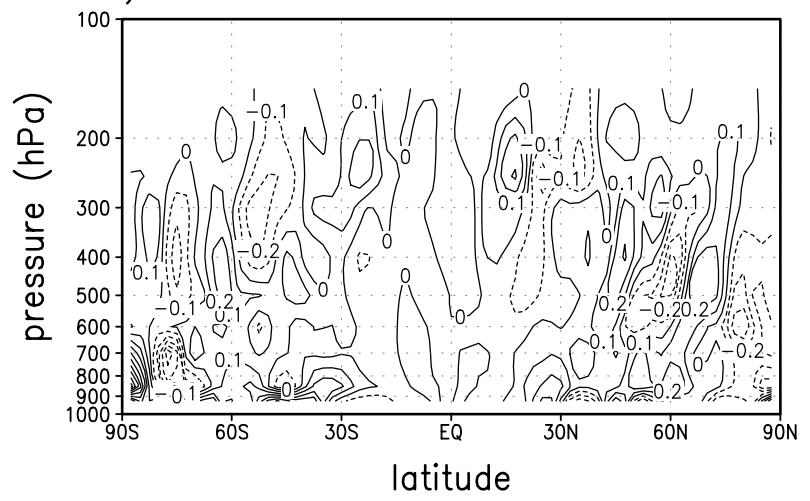

Fig. 5. Differences in PV transport for: (a) July 1997 minus 1995, (b) October 1997 minus 1995, (c) January 1998 minus 1996 and (d) April 1998 minus 1996. Units, $10^{-4} \mathrm{~ms}^{-2}$.

tributed to a decrease in PV transport in this region. The highest changes (PV transport was stronger in January 1998 than in January 1996) occur where the changes in eddy heat flux are the highest (in the middle and upper troposphere between $60^{\circ} \mathrm{N}-70^{\circ} \mathrm{N}$ ). In this region, eddy momentum flux also increases, but the changes are small.

In the case of the SH winter (July), there is a single maximum in eddy flux of sensible heat at low levels, around $60^{\circ} \mathrm{S}-70^{\circ} \mathrm{S}$ (Figs. 8a-b). This maximum is higher in 1997 than in 1995 . Between $60^{\circ} \mathrm{S}$ and $75^{\circ} \mathrm{S}$ from the surface to the upper troposphere, eddy heat flux increases in 1997 compared to 1995 (Fig. 8c). As is noted in Fig. 5a, the highest differences in PV transport also occur between $60^{\circ} \mathrm{S}$ and $75^{\circ} \mathrm{S}$ in the middle and upper troposphere. A secondary maximum in eddy heat flux differences between 1997 and 1995 is noted near $30^{\circ} \mathrm{S}$ in the middle and upper troposphere. In this region, there is a secondary maximum in PV transport differences (Fig. 5a). It can be seen in Figs. 9a and $\mathrm{b}$ that the maximum eddy momentum flux which occurs in July near $30^{\circ} \mathrm{S}$ in the upper troposphere is stronger in 1997 compared to that in 1995 . From $30^{\circ} \mathrm{S}$ to $50^{\circ} \mathrm{S}$ in the middle and upper troposphere, eddy momentum flux differences between 1997 and 1995 are the highest (Fig. 9c). In highlatitudes, there is little change in eddy momentum flux between the two years, although the up-gradient flux is somewhat weaker in 1997. Thus, it can be inferred from above that in SH winter (July), in the middle and upper troposphere near $30^{\circ} \mathrm{S}$ stronger eddy fluxes of heat and momentum contribute to stronger PV transport in 1997 compared to 1995 (see Figs. 5c, 8c, and 9c). However, the highest increase of PV transport which occurs in high-latitudes $\left(60^{\circ} \mathrm{S}-75^{\circ} \mathrm{S}\right)$ from the surface to the middle troposphere seems to be due mainly to the strongest eddy heat flux in 1997 in this region.

It can be seen in Figs. 5a and $\mathrm{c}$ that the differences in PV transport in El Niño 1997-1998 and La Niña 1995-1996 are higher in the $\mathrm{NH}$ winter (January) than in the SH winter (July), in agreement with the highest differences in eddy heat flux (Figs. 6c and 8c). As is shown in Figs. 5a and c, there is little difference in PV transport between the two contrasting years in the summer hemisphere (although it is slightly higher in the El Niño event). This is due to the fact that the changes in eddy fluxes of heat and momentum in the summer hemisphere are smaller than those in the winter hemisphere, as shown in Figs. 6c, 7c, 8c and 9c.

The results showed above indicate that the changes in PV transport in the two contrasting years are controlled mainly by the changes in eddy heat flux. The largest part of eddy heat flux transport in the troposphere in the middle and highlatitudes is by transient baroclinic waves. A suitable measure of the baroclinicity is provided by the Eady growth rate. This is a diagnostic which can be used to link features of the mean temperature structure with transient eddy activity. Eady 
a)

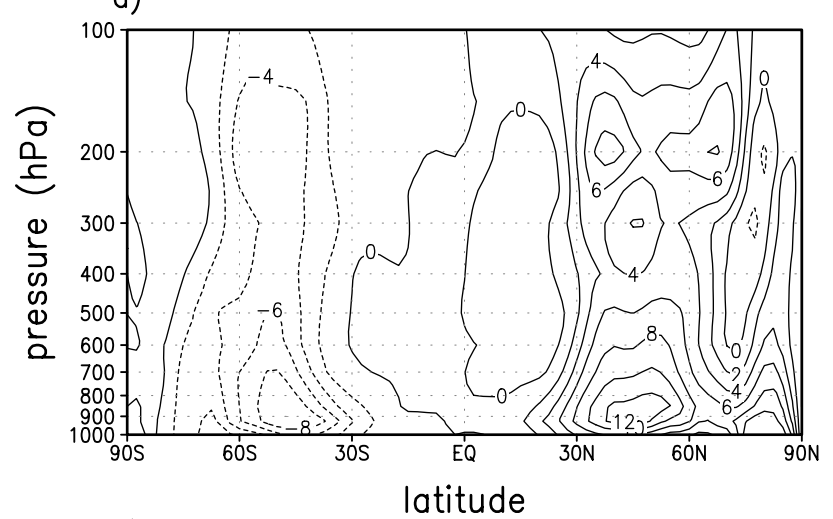

b)

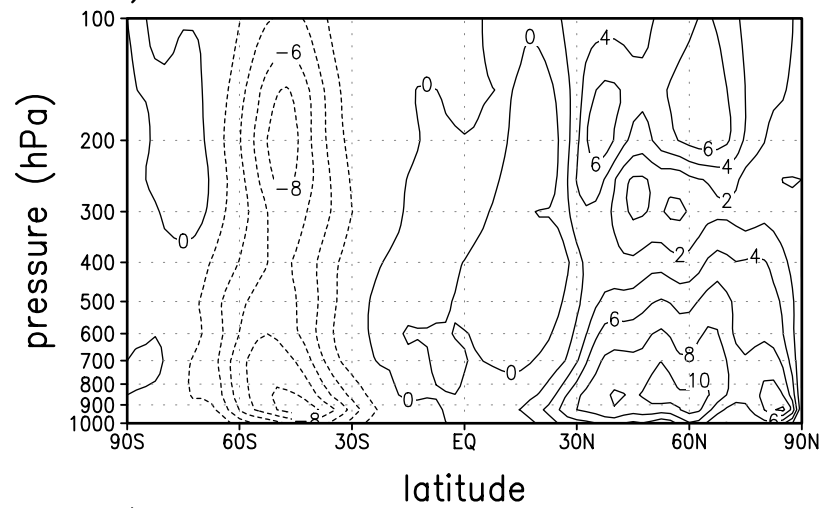

c)

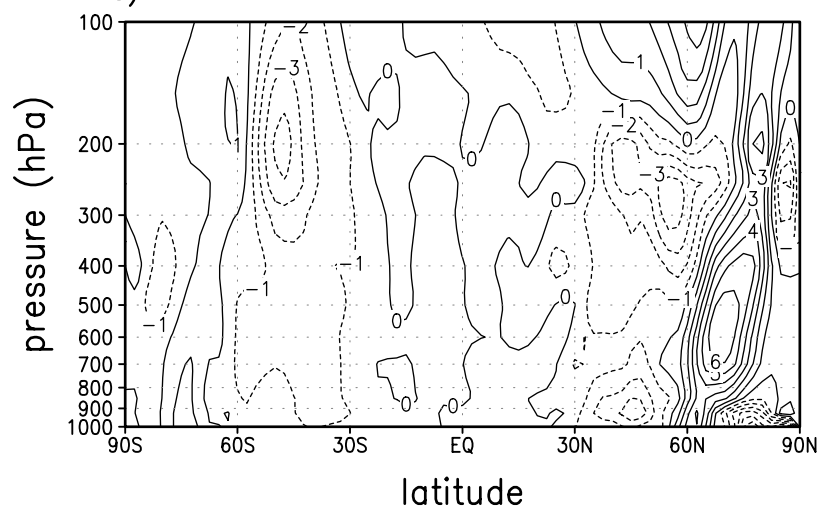

Fig. 6. Zonally-averaged eddy heat flux for January: (a) 1996, (b) 1998, and (c) Difference (1998 minus 1996). Units, $\mathrm{m} \mathrm{s}^{-1} \mathrm{~K}$.

growth rate is defined by $\sigma=0.31 f|\partial u / \partial z| / N$ (Lindzen and Farrel, 1980; Hoskins, 1983; Hoskins and Valdes, 1990), where $f$ is the Coriolis parameter; $N$, the Brunt-Vaisalla frequency; $z$, the upward vertical coordinate, and $u$ is the zonal flow. Very close to the surface, variations in $N$ would tend to dominate $\sigma$, but these are not relevant in nonlinear baroclinic instability. So, $\sigma$ should be determined by using finite differences over a depth of about $2 \mathrm{~km}$ (above the boundary layer).

Figures $10 \mathrm{a}$ and $\mathrm{b}$ show the latitudinal variation of $\sigma$ at $500 \mathrm{hPa}$, in units of day ${ }^{-1}$, for January (1996 and 1998) and July (1995 and 1997), respectively. As can be seen in these figures, in general, $\sigma$ is higher in the 1997-1998 El Niño than

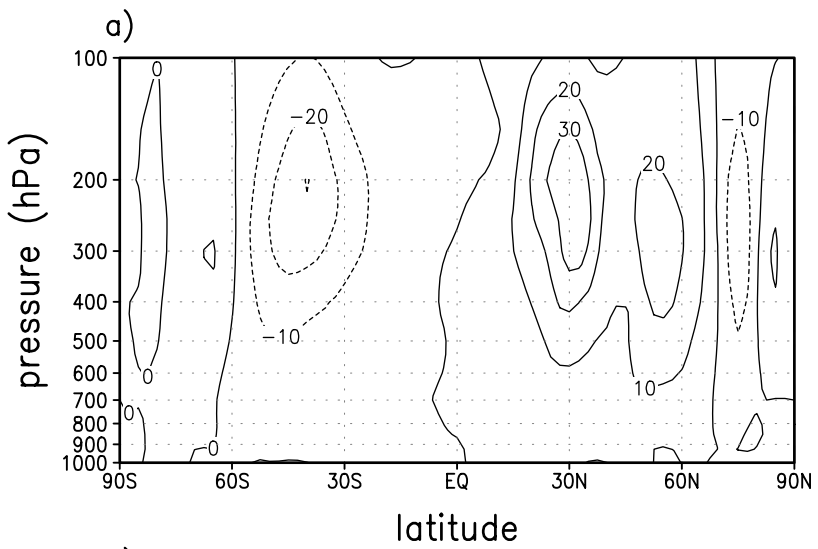

b)

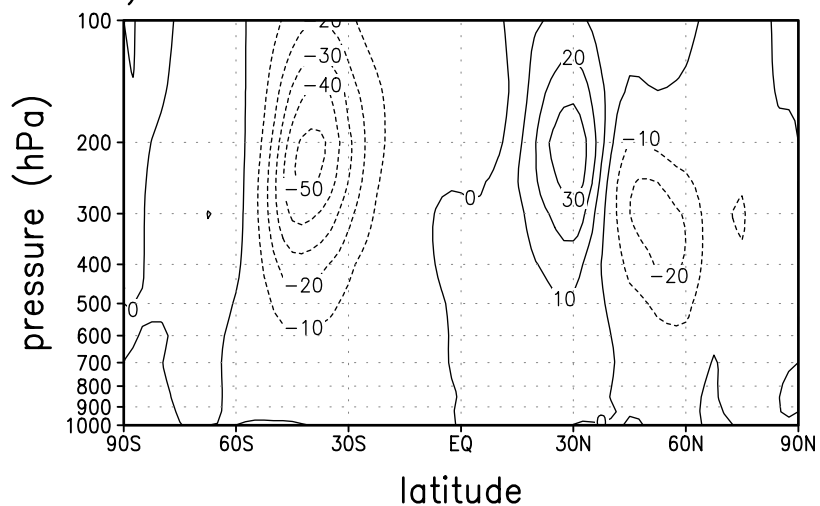

c)

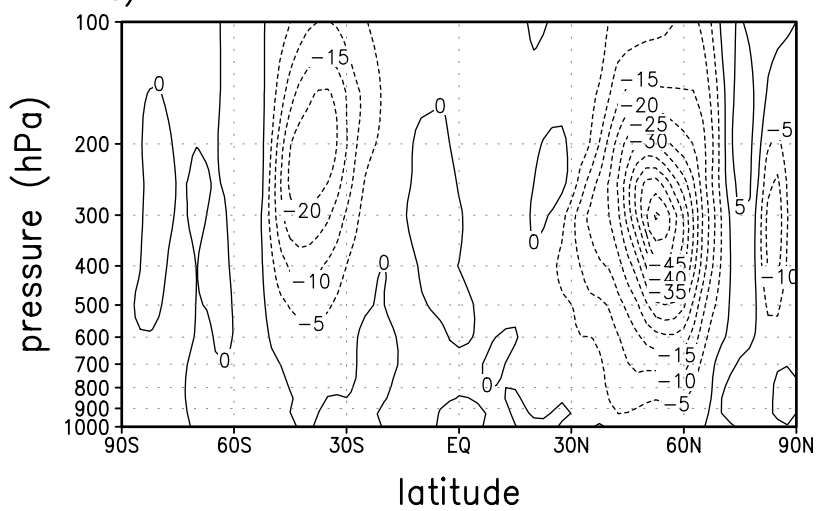

Fig. 7. Zonally-averaged eddy momentum flux for January: (a) 1996, (b) 1998, and (c) Difference (1998 minus 1996). Units, $\mathrm{m}^{2} \mathrm{~s}^{-2}$.

the 1995-1996 La Niña. The differences are highest in the winter hemisphere. During winter, the maxima values of $\sigma$ are almost the same near $30^{\circ} \mathrm{N}(\mathrm{S})$ (around $0.8 \mathrm{day}^{-1}$ ) in the two contrasting years (although $\sigma$ is slightly higher in January 1998 than January 1996). The highest differences occur in high-latitudes in both the hemispheres $\left(50^{\circ} \mathrm{N}-70^{\circ} \mathrm{N}\right.$, $60^{\circ} \mathrm{S}-75^{\circ} \mathrm{S}$ ). The highest differences in the baroclinicity in the high latitudes are in agreement with the highest changes in the eddy heat fluxes (Figs. 6c and 8c) and PV-transport (Figs. 5a and c). During summer, the values of $\sigma$ are slightly higher in the El Niño event than in the La Niña event.

The latitudinal variation of $\sigma$ is similar to that in the wind 
a)

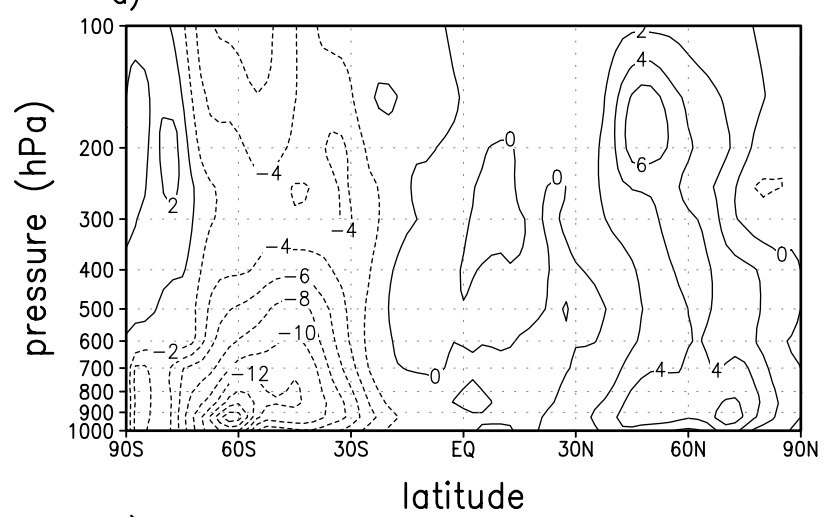

b)

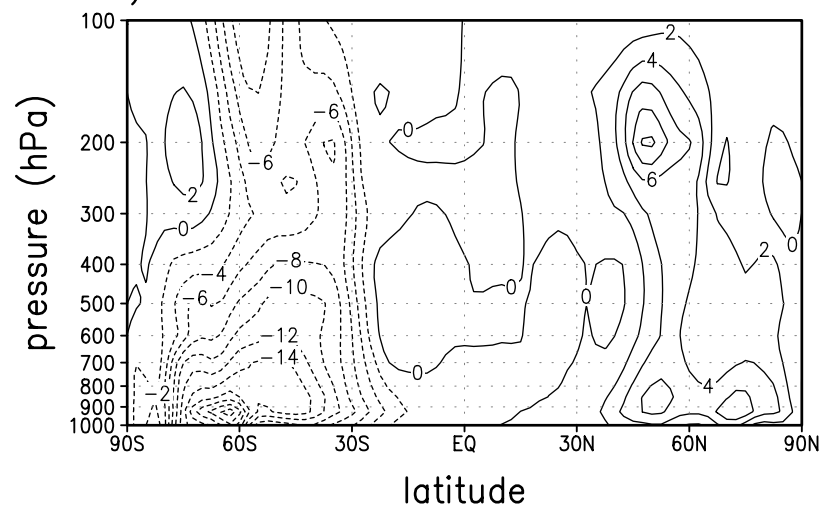

c)

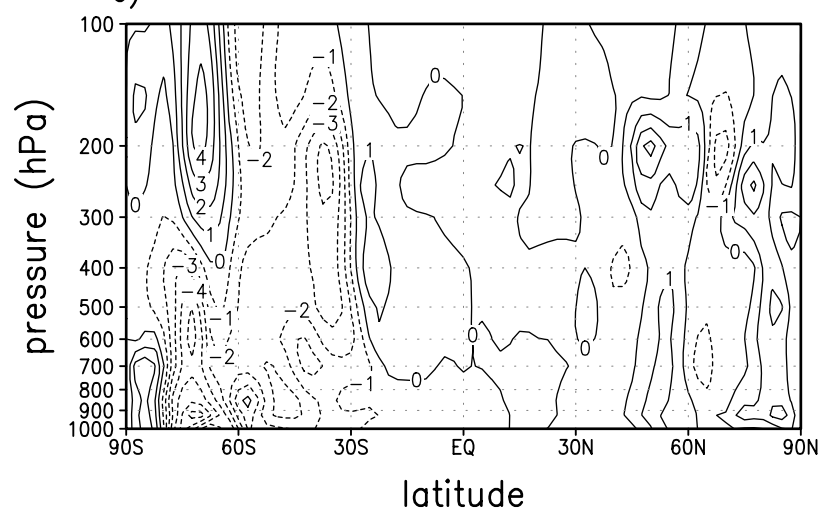

Fig. 8. Zonally-averaged eddy momentum flux for January: (a) 1995, (b) 1997, and (c) Difference (1997 minus 1995). Units, $\mathrm{m}^{-1} \mathrm{~K}$.

shear (Figs. 11a and b). The regions where $\sigma$ is maximum correspond approximately to those with higher values of the wind shear. The latitudinal variation of $\mathrm{N}$ (Figs. 12a and b) indicates that the static stability increases in high-latitudes from the summer to winter in both hemispheres. In the case of the $\mathrm{SH}$, the values of $\mathrm{N}$ in high-latitudes towards the pole are high even in summer (January). From Figs. 10 to 12, it can be inferred that the stronger values of $\sigma$ observed in the El Niño event are due to the increase in wind shear, since the values of $\mathrm{N}$ are almost the same in the two contrasting years or even higher in the El Niño event.

It is interesting to note from Figs. 10a and $\mathrm{b}$ and Figs. 13a-

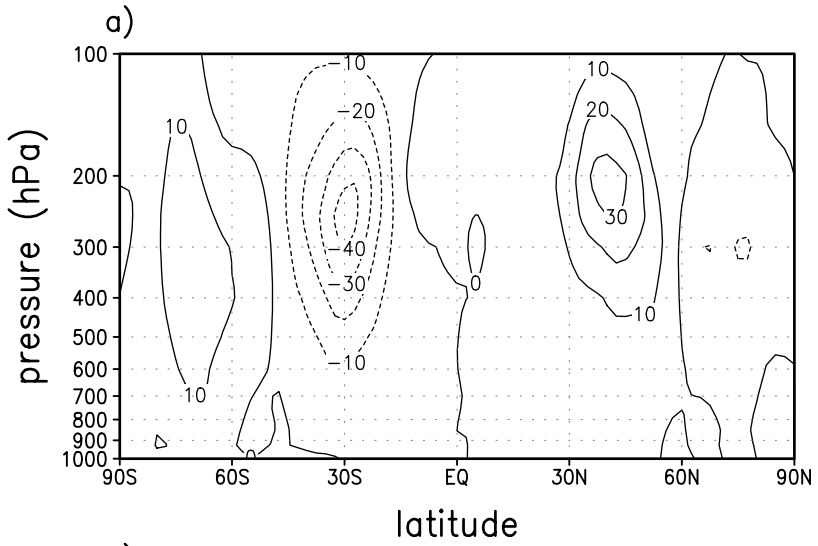

b)

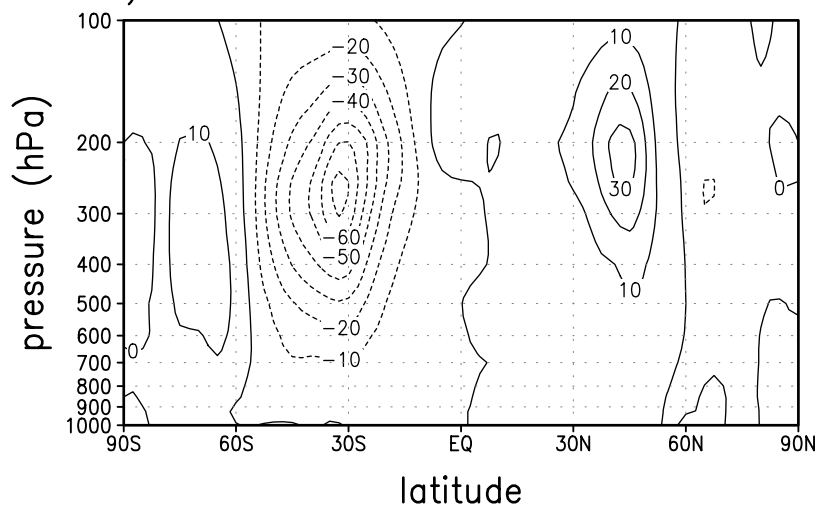

c)

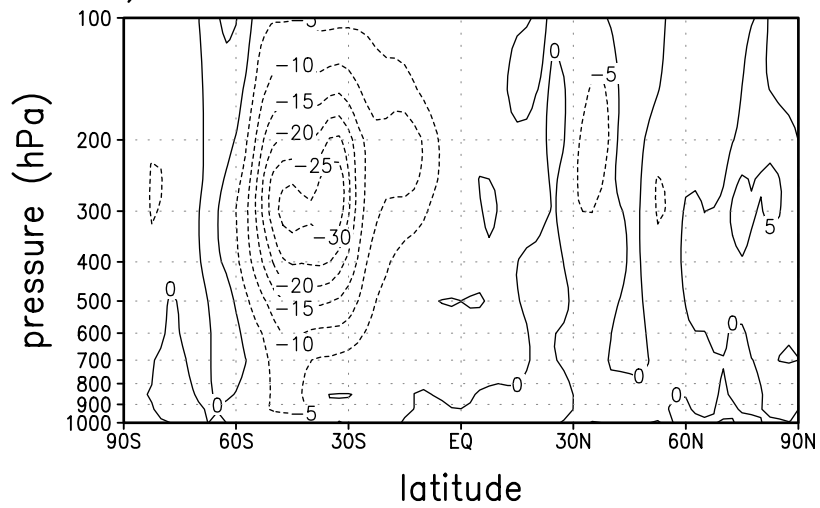

Fig. 9. Zonally-averaged eddy momentum flux for July: (a) 1995, (b) 1997, and (c) Difference (1997 minus 1995). Units, $\mathrm{m}^{2} \mathrm{~s}^{-2}$.

$\mathrm{d}$ that the latitude regions with the highest values of $\sigma$ correspond approximately to the regions where the zonal winds are highest. From Figs. 13a-d, it can be seen that the zonal winds are stronger in the El Niño event than in the La Niña event, although the location of the jet streams are almost the same in the two contrasting years. In the case of the $\mathrm{SH}$, there are two maxima of $\sigma$ in July 1997 (around 0.8 day $^{-1}$ ) and a double jet is observed, while in July 1995 a single jet is noted, associated with only one maximum of $\sigma$.

Figures 14a-d show EP cross sections for January 19961998 and July 1995-1997, respectively. As can be seen, EP divergence contours and EP fluxes are stronger in the winter hemisphere in both the contrasting years. The general pattern 
a)

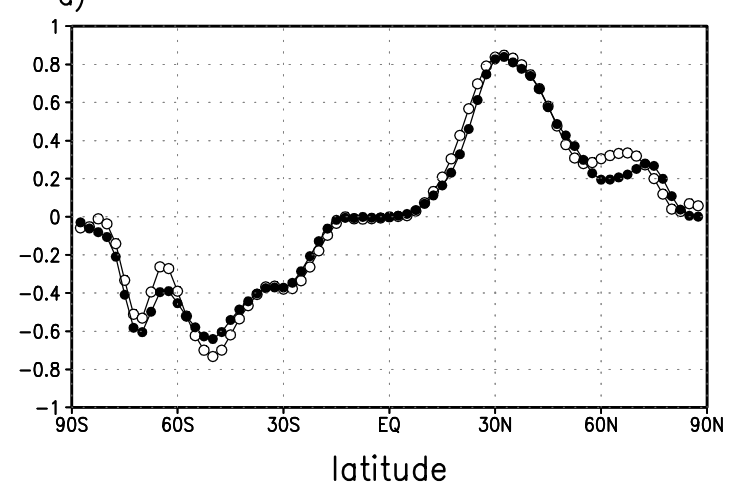

b)

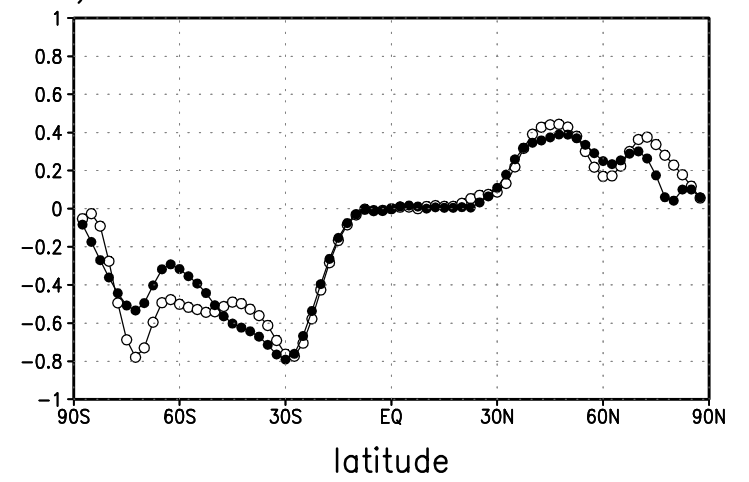

Fig. 10. Latitudinal variation of Eady growth rate for: (a) January 1996 and January 1998, and (b) July 1995 and July 1997. El Niño event 1997-1998 is indicated by open circles and La Niña 19951996 is represented by closed circles. Units, day ${ }^{-1}$.

of EP cross sections are similar to that of the time-averaged life cycle of nonlinear baroclinic waves obtained from observations (Randel and Stanford 1985a, b) and model simulations (Simmons and Hoskins, 1980; Hoskins, 1983). There is EP convergence over most of the troposphere, which corresponds to down-gradient PV transport (Figs. 1a and 2a, and Figs. 1c and 2c) in the regions where PV gradient is positive (Figs. 3a and 4a, and Figs. 3c and 4c). EP divergence is found near the surface and corresponds also to down-gradient positive PV transport because PV gradient is weak or mostly negative in this region. The poleward heat flux dominates from the surface to the middle troposphere. So, Rossby wave group propagation is directed upwards away from the surface in the lowest levels and above $500 \mathrm{hPa}$ the EP vectors turn equatorward, becoming approximately horizontal in the upper levels. This radiation towards the tropics is accompanied by large poleward momentum fluxes (Edmon et al., 1980). In the winter hemisphere, EP convergence is noted over almost the entire troposphere from $30^{\circ} \mathrm{N}(\mathrm{S})$ towards the poles and EP divergence is found on the poleward side at low levels. EP convergence indicates that waves tend to decelerate the zonal flow with zonal energy becoming converted into wave energy. This configuration of EP cross sections is associated with northward PV flux at low levels and southward PV flux in the upper troposphere, as shown in Figs. 1a and c and

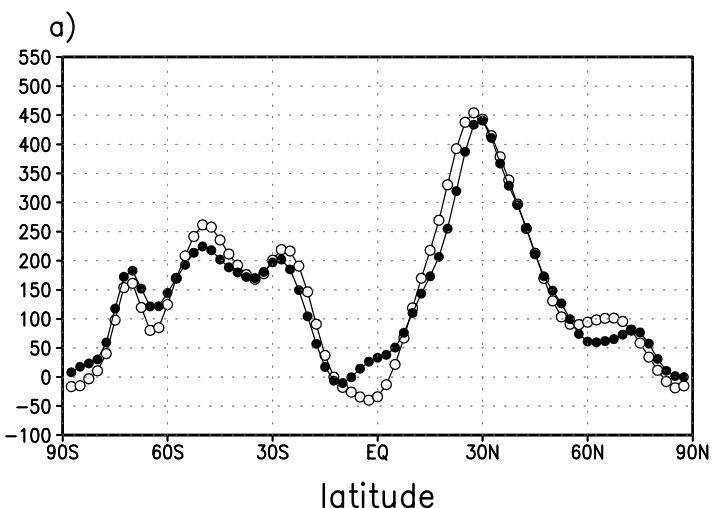

b)

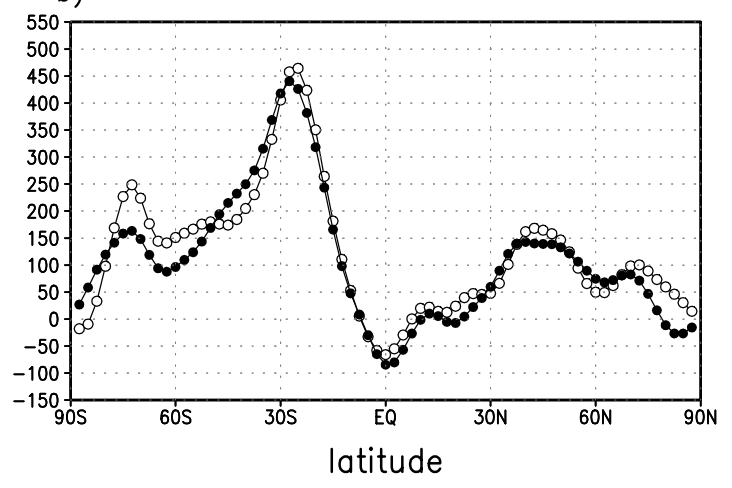

Fig. 11. Same as Fig. 9 but for the shear wind.

a)

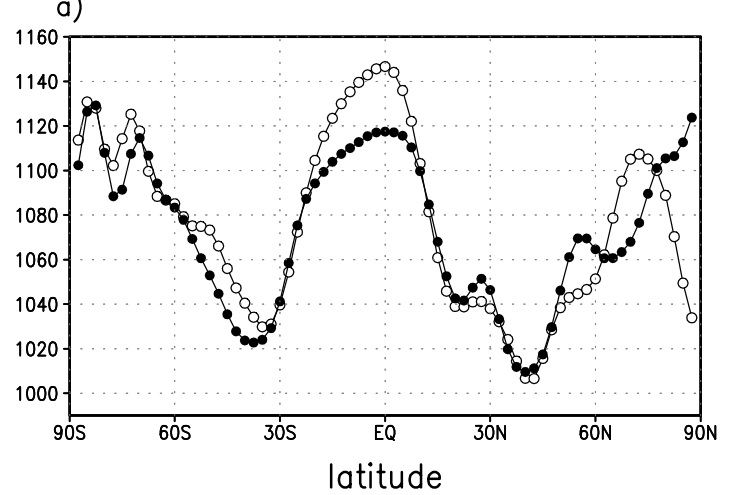

b)

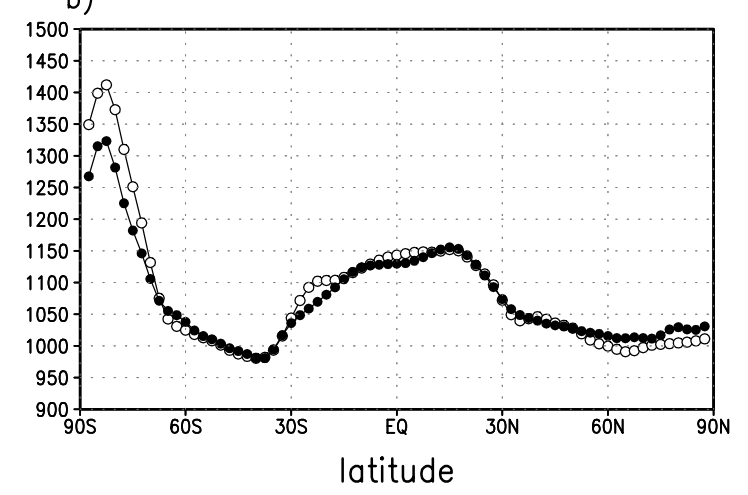

Fig. 12. Same as Fig. 10 but for the Brunt-Vaisalla frequency. 


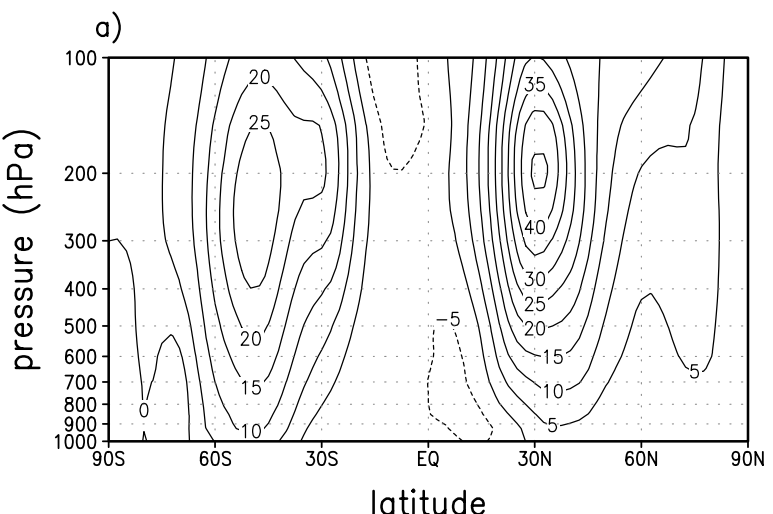

c)

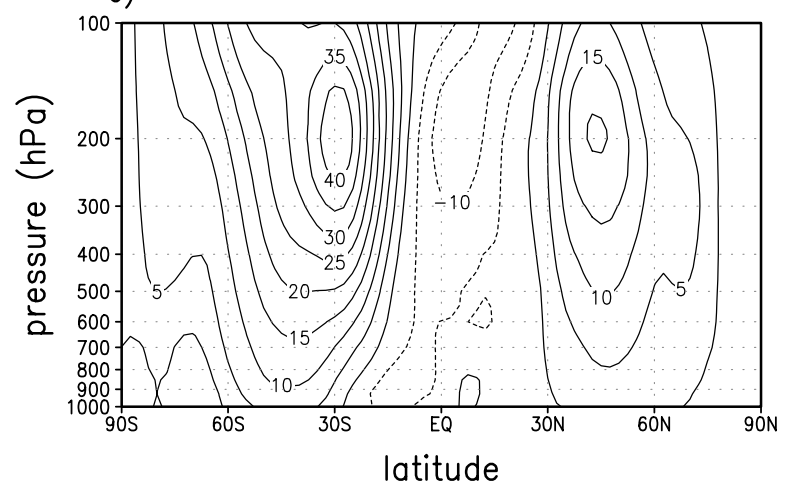

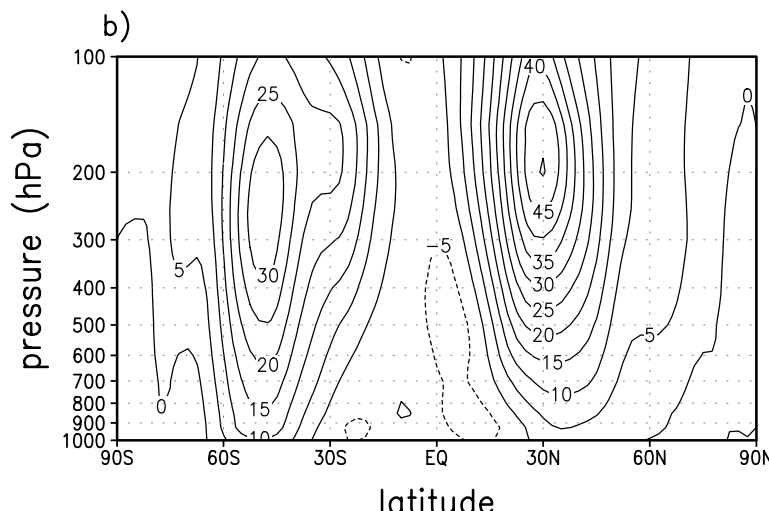

d)

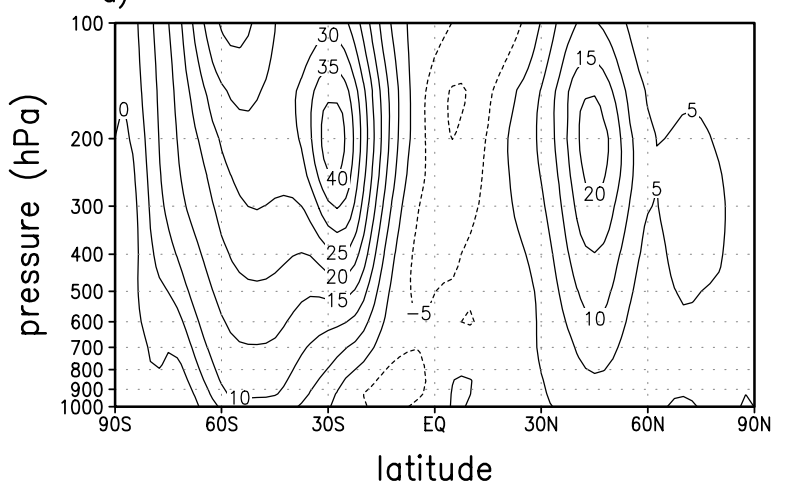

Fig. 13. Zonal wind for: (a) January 1996, (b) January 1998: (c) July 1995, and (d) July 1997. Units, $\mathrm{m} \mathrm{s}^{-1}$.

Figs. 2a and c.

EP vectors and EP divergence contours are stronger in January 1998 than January 1996, and stronger in July 1997 than in July 1995. Thus, the dynamical processes discussed above are intensified during the 1997-1998 El Niño compared with the 1995-1996 La Niña and consequently, the activity of baroclinic waves is stronger. As in the case of PV transport (Figs. 5a and c), the differences in EP cross sections are higher in winter in both hemispheres. In summer, there is little difference in EP cross sections between the two contrasting years, as in the case of PV transport.

Thus, analysis on PV transport and EP cross sections show that in the winter the baroclinicity is stronger in the El Niño year compared to the La Niña year in both hemispheres. This corroborates with the results from earlier studies which indicate that the occurrence of cyclogenesis is more when the Southern Oscillation index is negative and less when it is positive (Gan and Rao, 1991). However, since in the present work only two episodes of El Niño and La Niña were taken into account, further analysis considering a larger number of events must be done to reach statistical significance.

\section{Summary and conclusions}

In this paper, the meridional PV transport and EP flux are studied for two contrasting years: 1995-1996 (La Niña) and 1997-1998 (El Niño). Seasonal variation of eddy fluxes of heat, momentum and PV are investigated, in order to study the activity of baroclinic waves in these years. For this purpose, monthly means are computed for the periods where the events are stronger.

The results showed that in the winter of both hemispheres PV transport is stronger in El Niño 1997-1998 than in La Niña 1995-1996 (in the NH the changes are higher than in the $\mathrm{SH})$. The highest differences in $\mathrm{PV}$ transport occurs in high-latitudes $\left(60^{\circ} \mathrm{N}-70^{\circ} \mathrm{N}\right.$ and $\left.60^{\circ} \mathrm{S}-75^{\circ} \mathrm{S}\right)$ in the middle and upper troposphere. This is associated with stronger eddy heat flux in the El Niño 1997-1998 than in the La Niña 19951996 in these regions. Another region where PV fluxes are stronger in El Niño event than in La Niña event is found around $30^{\circ} \mathrm{S}-40^{\circ} \mathrm{S}$ in the middle and upper troposphere. This is associated with both stronger eddy fluxes of heat and momentum in this region. However, the changes in PV transport are lower in this region than around $60^{\circ} \mathrm{S}-75^{\circ} \mathrm{S}$.

Since in both hemispheres the highest differences in PV transport occur in high-latitudes (where the differences in the eddy heat fluxes are also the highest), the changes in PV transport seems to be controlled mainly by the changes in eddy heat flux by baroclinic waves. The highest differences in Eady growth rate $(\sigma)$ between the two contrasting years are found again in the winter hemisphere in high-latitudes (from $50^{\circ} \mathrm{N}$ to $70^{\circ} \mathrm{N}$ and from $60^{\circ} \mathrm{S}$ to $75^{\circ} \mathrm{S}$ ), indicating that the baroclinicity is stronger in El Niño 1997-1998 than in La Niña 1995-1996. The highest values of $\sigma$ observed in the El Niño event may be due to the increase in wind shear, 
a)

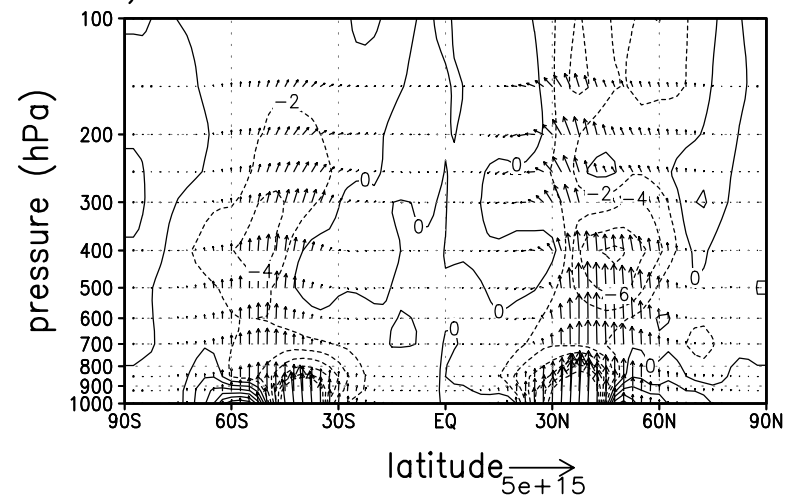

c)

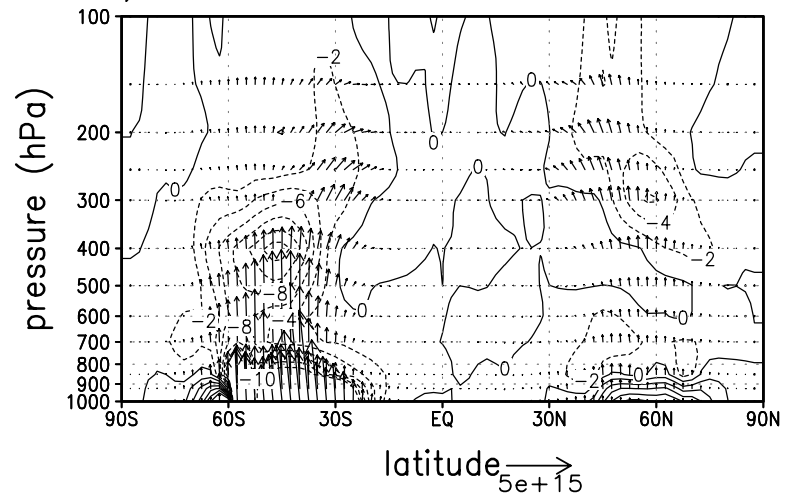

b)

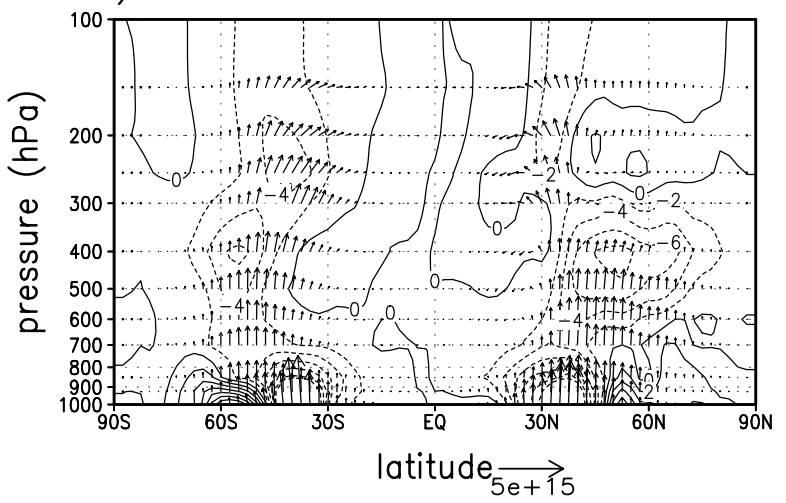

d)

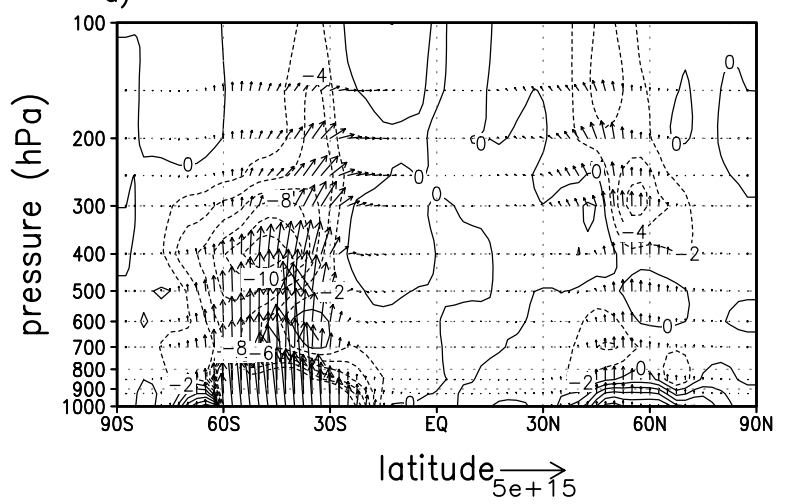

Fig. 14. Zonally-averaged EP cross sections for (a) January 1996, (b) January 1998; (c) July 1995, and (d) July 1997. The contour interval is $5.0 \times 10^{15} \mathrm{~m}^{3}$. The horizontal arrow scale for EP flux in units of $\mathrm{m}^{3}$ is indicated at bottom right.

since the values of the static stability are almost the same in the two contrasting years or even higher in the El Niño event. The highest values of the baroclinicity are associated with stronger eddy heat flux, PV transport and zonal wind in the El Niño event than in the La Niña event. In the SH, there are two maxima of $\sigma$ in July 1997 (around 0.8 day $^{-1}$ ) near $30^{\circ} \mathrm{S}$ and in the high-latitudes, which are associated with the double jet observed in this period, while in July 1995 a single jet is observed, associated with only one maximum of $\sigma$ near $30^{\circ} \mathrm{S}$.

EP cross sections were calculated for January 1996-1998, and July 1995-1997 and the results showed that EP fluxes and EP divergence contours are stronger in the winter hemisphere. The highest differences in EP cross sections between El Niño 1997-1998 and La Niña 1995-1996 also occur in the winter in both hemispheres. EP vectors and EP divergence contours are stronger in the El Niño event than in the La Niña event, indicating stronger activity of the baroclinic waves. The differences are higher in the NH winter in relation to the SH winter. This is compatible with the configurations of eddy heat flux and PV transport. In the summer of both hemispheres, there is little difference in PV transportEP cross sections between the El Niño 1997-1998 and the La Niña 1995-1996. However, in general PV flux-EP divergence are slightly higher in the El Niño event than in the La Niña event. This is in agreement with sligthy higher eddy heat fluxes, Eady growth rate and zonal winds in El Niño event than in La Niña event.

Thus, the results of the present study showed that baroclinic activity is stronger in El Niño year than in La Niña year. This corroborates with the results obtained from earlier studies which indicated that the occurrence of cyclogenesis is more in years when the Southern Oscillation index is negative and less in years when it is positive (Gan and Rao, 1991). However, the conclusions of the present work must be taken with care since only two episodes of El Niño and La Niña were considered. Analysis with a larger number of events must be done in order to reach statistical significance.

Acknowledgements. Topical Editor J. P. Duvel thanks B. Legras for his help in evaluating this paper.

\section{References}

Barnston, A. G., Leetmaa, A., Kousky, V. E., et al.: NCEP forecasts for the El Niño of 1997-98 and its US impacts, Bull. Amer. Meteor. Soc., 80, 1829-1852, 1999.

Changnon, S. A.: Impacts of 1997-98 El Niño-generated weather in United States, Bull. Amer. Meteor. Soc., 80, 1819-1827, 1999.

Charney, J. G. and Stern, M.: On the stability of internal baroclinic jets in a rotating atmosphere, J. Atmos. Sci., 19, 159-172, 1962. 
Chen, W. Y.: The climate of spring 1983 - A season of persistent global anomalies associated with El Niño, Mon. Wea. Rev., 111, 2371-2384, 1983.

Coughlan, M. J.: Retrospective on the 1997/1998 El Niño event, CLIVAR Exchanges, 4, 7-8, 1999.

Edmon, H. J., Hoskins, B. J., and McIntyre, M. E.: Eliassen-Palm cross sections for the troposphere, J. Atmos. Sci., 37, 2600-2616, 1980.

Franchito, S. H. and Rao, V. B.: Quasi-geostrophic potential vorticity in the Northern and Southern Hemisphere and simple climate models, J. Meteor. Soc. Japan, 69, 233-239, 1991.

Gan, M. A. and Rao, V. B.: Surface cyclogenese over South America, Mon. Wea. Rev., 119, 1293-1302, 1991.

Grimm, A. M., Ferraz, S. E. T., and Gomes, J.: Precipitation anomalies in Southern Brazil associated with El Niño and La Niña events, J. Climate, 11, 2863-2880, 1998.

Hansen, J. W., Jones, J. W., Kiker, C. F., and Hodges, A. W.: El Niño-Southern Oscillation impacts on winter vegetable procuction in Florida, J. Climate, 12, 92-102, 1999.

Hoskins, B. J.: Modelling of the transient eddies and their feedback on the mean flow. In: Large-scale dynamical processes in the atmosphere, (Eds) Hoskins, B. J. and R. Pearce, Academic Press, 396, 1983.

Hoskins, B. J. and Valdes, P. J.: On the existence of storm-tracks, J. Atmos. Sci., 47, 1854-1864, 1990.

Kalnay, E., Kanamitsu. M., Kistler, R., et al.: The NCEP/NCAR 40 year reanalysis project, Bull. Amer. Meteor. Soc., 77, 437-471, 1996.

Kayano, M. T., Rao, V. B., and Moura, A. D.: Water circulation and atmospheric water vapour, Int. J. Climatol., 9, 243-251, 1989.

Kiladis, G. N. and Diaz, H. F.: Global climatic anomalies associated with extremes in the Southern Oscillation, J. Climate, 2, 1069-
1090, 1989.

Kousky, V. E., Kagano, M. T., and Cavalcanti, I. F. A.: A review of the Southern Oscillation: oceanic-atmosphericcirculation changes and related rainfall anomalies, Tellus, 36A, 490-504, 1984.

Lindzen, R. S. and Farrell, B.: A simple approximate result for the maximum growth rate for baroclinic instabilities, J. Atmos. Sci., 37, 1648-1654, 1980.

Neelin. J. D., Jin, F.-F., and Syu, H.-H.: Variations in ENSO phase locking, J. Climate, 13, 2570-2590, 2000.

Randel, W. J. and Stanford, J. L.: The observed life cycle of a baroclinic instability, J. Atmos. Sci., 42, 1364-1373, 1985a.

Randel, W. J. and Stanford, J. L.: An observational study of medium scale wave dynamics in the Southern Hemisphere summer. Part I: Wave structure and energetics, J. Atmos. Sci., 42, 1172-1188, 1985 b.

Ropelewski, C. F. and Halpert, M. S.: Quantifying Southern Oscillation-precipitation relationships, J. Climate, 9, 1043-1059, 1996.

Simmons, A. J. and Hoskins, B. J.: The lyfe cycles of some nonlinear baroclinic waves. J. Atmos. Sci., 35, 414-432, 1980.

Trenberth, K. E., Branstator, G. W., Karoly, D., Kumar, A., Lau, N.C., and Ropelewski, C.: Progress during TOGA in understanding and modeling global teleconnections associated with tropical sea surface temperatures, J. Geophys. Res., 103 (C7), $14291-$ 14324, 1998.

Wang, C. and Weisberg, R. H.: The 1997-1998 El Niño evolution relative to previous El Niño events, J. Climate, 13, 488-501, 2000.

Wiin-Nielsen, A. and Sela, J.: On the transport of quasi-geostrophic potential vorticity, Mon. Wea. Rev., 99, 447-459, 1971. 